Prospective first-generation college students: A social-cognitive perspective.

By: Melinda M. Gibbons and L. DiAnne Borders

This is the pre-peer reviewed version of the following article:

Gibbons, M. M., \& Borders, L. D. (2010). Prospective first-generation college students: A social-cognitive perspective. Career Development Quarterly, 58(3), 194-208.

which has been published in final form at DOI: 10.1002/j.2161-0045.2010.tb00186.x. Figures and/or pictures may be missing from this format of the document.

\begin{abstract}
:
The authors investigated differences in college-going expectations of middle school students who would be the 1st in their families to attend college. Social-cognitive career theory (SCCT; R. W. Lent, S. D. Brown, \& G. Hackett, 1994) was used to examine college-related expectations in 272 seventh-grade students. Differences were found between prospective 1st-generation college students (PFGCSs) and their non-PFGCS peers, with the former group demonstrating lower self-efficacy, higher negative outcome expectations, and more perceived barriers. Path analysis demonstrated partial support for the SCCT model. An alternative model for PFGCSs is proposed.
\end{abstract}

Keywords: college plans | middle school students | first generation college students | selfefficacy | college expectations

Article:

To date, little research has been conducted that goes beyond descriptive characteristics of firstgeneration college students (FGCSs) prior to their arrival to college. This group contains more minorities, is more likely to be from lower income families, and has lower academic achievement compared with their peers whose parents have some experience in college (Nunez \& Cuccaro-Alamin, 1998; Terenzini, Springer, Yaeger, Pascarella, \& Nora, 1996). Additionally, FGCSs have higher attrition rates once they arrive at college than do their non-FGCS peers (Nunez \& Cuccaro-Alamin, 1998). Because taking rigorous course work in high school, by itself, is not enough to even the odds (Horn \& Nunez, 2000), it seems important to assess for other differences that could influence this group's college decision making. In this study, we investigated social-cognitive variables of students who would be the first in their families to attend college and whose parents had some level of postsecondary education.

For the purposes of this study, the term FGCSs refers to students whose parents have no formal education beyond high school and who attend college. The term prospective first-generation college students (PFGCSs) are middle and high school students whose parents lack education 
beyond high school and who have not yet graduated themselves. Finally, students whose parents have any college education, including 2- or 4-year college and regardless of degree status, are termed non-FGCSs or non-PFGCSs when the students are specifically of middle or high school age.

More and more, students in general are planning to continue their education beyond high school. In fact, the majority of middle and high school students intend to enter into some type of postsecondary education after high school graduation (Venezia, Kirst, \& Antonio, 2003). Yet, the connection between intentions and actual college attendance and completion does not occur for many students. Although most students plan to continue their education, the national average of students continuing directly to any type of college for 2000 was 56.7\% (National Information Center for Higher Education Policymaking and Analysis, 2002). Reasons for tire disconnect between plans and actions have yet to be fully identified.

FGCSs

One group of students in particular--those whose parents have no formal education beyond high school--experience significant difficulties related to college going. Slightly more than $25 \%$ of 1992 high school graduates were PFGCSs (Horn \& Nunez, 2000), and 43\% of all students (including non-traditional-age students) entering postsecondary education were FGCSs (Nunez \& Cuccaro-Alamin, 1998).

In terms of educational attainment, FGCSs tend to perceive less family support for attending college (York-Anderson \& Bowman, 1991), are less likely to take college preparatory course work (Horn \& Nunez, 2000), and are more likely to have lower grade point averages during their 1st year of college (Warburton, Bugarin, Nunez, \& Carroll, 2001) compared with students with college-educated parents. In addition, FGCSs are less likely to complete college than are their non-FGCS peers (Nunez \& Cuccaro-Alamin, 1998). These differences hold true even when controlling for family income, academic preparation, and ethnicity (Horn \& Nunez, 2000; Terenzini et al., 1996), suggesting first-generation status is a unique contributor to differences in college preparation, attendance, and persistence.

Clearly, this population needs assistance in order to succeed at the college level. Unfortunately, most research to date has been focused on these students once they arrive at college rather than 
on factors that influence their decision making before they arrive at college--or decide not to attend. In fact, students begin making critical educational planning decisions as early as middle school. Thus, the critical need to study middle school students who would be the first in their families to attend college is clear.

Social-Cognitive Career Theory (SCCT) With Middle School Students

SCCT (Lent, Brown, \& Hackett, 1994) is particularly relevant to an examination of middle school students who would be the first in their family to attend college. SCCT was developed to explain "processes through which (a) academic and career interests develop, (b) interests, in concert with other variables, promote career-relevant choices, and (c) people attain varying levels of performance and persistence in their educational and career pursuits" (Lent \& Brown, 1996, p. 311). SCCT is composed of three major constructs that interact with each other to affect career and educational intentions and actions. These constructs--self-efficacy, outcome expectations, and goals--are also directly and indirectly affected by background and proximal influences, along with genetic predispositions and learning experiences (Lent et al., 1994). SCCT has been found to explain the career and educational experiences of a variety of populations, including minority students (Flores \& O'Brien, 2002) and international students (Lent, Brown, Nota, \& Soresi, 2003).

Recently, researchers (e.g., Fouad \& Smith, 1996; Turner \& Lapan, 2002) have examined the fit of SCCT with middle school students and found that the data do support the SCCT model. Fouad and Smith (1996) assessed math- and science-related self-efficacy, outcome expectations, and interests of 380 seventh and eighth graders. In place of career-choice goals, they substituted the more developmentally appropriate construct of choice intentions. Fouad and Smith found the SCCT model worked with both male and female students and with Hispanic, African American, and White students. Turner and Lapan (2002) also found that SCCT constructs predicted career interests for all types of careers and that perceived parent support directly affected self-efficacy expectations.

SCCT is directly applicable to PFGCSs in that the theory links academic and career pursuits while taking into consideration variables such as back-ground and contextual influences on these pursuits. Social and economic factors, personal perceptions, and belief systems, critical issues for first-generation students, are all accounted for within the SCCT model (Lent et al., 1994). 
Researchers have identified differences between FGCSs and other college students in each of these areas. Thus, by identifying first-generation status as a background characteristic, the framework of SCCT makes it possible to research differences in social-cognitive variables related to college going and how each of these directly or indirectly affects educational and career intentions in middle school students.

We used the SCCT model of career development to study the college-going expectations of PFGCSs as compared with their non-PFGCS peers. We studied person inputs, such as gender and ethnicity; background variables that included first-generation status; and college-going variables, such as self-efficacy, outcome expectations, barriers, and social supports (school and parent); the goals variable was replaced with the more developmentally appropriate strength of intentions. We hypothesized PFGCSs would have lower expectations and expectations associated with college going, perceive more barriers, and identify fewer social supports than would their peers whose parents had some college-going experience (non-PFGCSs). On the basis of previous research (e.g., Horn \& Nunez, 2000), we also tested for the effects of gender and ethnicity on college-going expectations. In addition, we predicted the SCCT model would be a good fit in explaining the career and educational development of the PFGCSs.

Method

Participants

Participants were 272 seventh graders from four middle schools in a single southeastern state. We chose seventh graders because they are in the midst of their middle school careers but have not yet completed high school registration, which could have biased the results because it encourages thought about career and college planning.

To maximize the number of PFGCS participants, we carefully selected schools that had a high percentage of students on free or reduced lunch and/or a high minority student population. (Both lower socioeconomic status and minority status are characteristics of PFGCSs.) A total of 275 students returned parental consent forms and completed the survey; 3 did not indicate parent education level and were eliminated from the study, leaving a total sample size of 272 seventhgrade students. Participation rates at each school ranged from $29.6 \%$ to $43.2 \%$, with an average 
of $37.66 \%$. At each school, slightly more girls $(n=154)$ than boys $(n=118)$ participated in the survey. Their average age was 12.65 years $(\mathrm{SD}=.61$, range $=12-14$ years $)$.

Of this sample, 109 participants were PFGCSs. The representation of White (34.2\%; PFGCS $n=$ 15, non-PFGCS $n=78$ ), African American (30.5\%; PFGCS $n=24$, non-PFGCS $n=59$ ), and Hispanic/Latino (23.9\%; PFGCS $n=58$, non-PFGCS $n=7$ ) students closely approximated the entire school population at each site. The remaining students, including some multiracial students, were classified as "other ethnicity" (11\%; PFGCS $n=12$, non-PFGCS $n=18)$. (Percentages do not total 100\% because of rounding.)

Measures

Participants completed the study instruments in the following order.

College-going self-efficacy. The College-Going Self-Efficacy Scale (Gibbons, 2005) was created to measure college-going expectations before arriving at college. The development of the scale was based on previous research (Horn \& Nunez, 2000; Warburton et al., 2001) that suggested college-going self-efficacy was a combination of perceived ability to complete the tasks needed to arrive at college and the ability to stay there. The scale consists of 15 items related to college attendance and 16 items related to college persistence. In the College Attendance subscale, students respond to the prompt "How sure are you about being able to do the following," using a 4-point Likert-type scale ranging from 1 (not at all sure) to 4 (very sure). Items reflect financial issues, issues related to ability, family-related issues, and decision-making skills. For the Persistence subscale, participants answer using the hypothetical situation that they did go to college and use the same Likert-type scale. Items address issues of finances, ability, family, and life skills. Higher scores indicate higher college-going self-efficacy perceptions. In our study, the scale had a coefficient alpha of .94.

We conducted a principal-component exploratory factor analysis with a varimax rotation method to add to evidence of validity. Six components had an eigenvalue greater than 1.0, although a significant reduction occurred after the first component. Because of the types of factors we had predicted for the scale, a two-factor approach was also attempted. The results revealed that a two-factor solution (Attendance and Persistence) appeared to be a good fit to explain collegegoing self-efficacy because the items primarily loaded on the predicted factors. Even when we 
used a liberal item-to-assignment rule (i.e., .30 or more and .25 or less), however, many of the items did not clearly load on one factor. A correlation matrix determined the relationship between the two components to be very strong, $\mathrm{r}(\mathrm{l})=.77, \mathrm{P}<.01$. Because of the strong correlation, it appears although college-going self-efficacy is determined by both attendance and persistence, a total scale score is most appropriate for use in analysis of differences.

Perceived barriers to college going. The Perception to Educational Barriers Scale (PEB; McWhirter, 2000) measures 28 variables that might be barriers to continuing education after high school on a 4-point Likert-type scale ranging from I (not at all likely) to 4 (definitely), with higher scores indicating more perceived barriers. For sophomores in high school, PEB scores significantly correlated with a similar measure of career opportunities, and higher PEB scores were associated with lower career decision-making self-efficacy (McWhirter, Rasheed, \& Crothers, 2000). The PEB also had acceptable reliability (Cronbach's alpha $=.90$ ) when used with first-generation students (Kenny, Blustein, Chaves, Grossman, \& Gallagher, 2003). For this study, we used only the Likelihood subscale (measure of barriers occurring) because pilot testing revealed the other subscales (measures of coping efficacy) were too abstract for seventh graders to understand (see Gibbons, 2005).

Researchers (e.g., Lent, Brown, \& Hackett, 2000; Lent et al., 2003) have found the effects of barriers on self-efficacy tend to be much weaker than the effects of social supports and have suggested the existing barriers scales may not be comprehensive enough. We conducted a new review of the qualitative and quantitative research on barriers to college going and identified multiple barrier themes: uncertainty about career plans, unsafe environment, finances, lack of social support, gender and ethnic discrimination, lack of role models, negative role models, family issues, lack of long-term guidance, lack of preparation, low academic skills, and not fitting in with others (e.g., Jackson \& Nutini, 2002; Luzzo, 1993; Rojewski \& Hill, 1998; Vargas, 2004). With permission from the original author (i.e., McWhirter, 2000), we categorized the 28 original items by these themes and added 17 items to themes for which no items existed, for a new total of 45 perceived barriers. This we refer to as the Perception to Educational Barriers Scale-Revised (PEB-R). In our study, the Cronbach's alpha for the revised Likelihood subscale was .93.

Parent and school personnel support. The Child and Adolescent Social Support Scale (CASSS; Malecki, Demaray, \& Elliott, 2000) measures a person's perception of general or specific support, which either helps overall functioning or acts as a shield against negative outcomes (Malecki, Demaray, \& Elliott, 2004). The CASSS is appropriate for use with 3rd- through 12thgrade students. Students rate each item by frequency using a 6-point Likert-type scale ranging 
from 1 (never) to 6 (always). For this study, only subscales measuring school personnel and parental support frequency were used.

On the basis of three diverse middle school samples, Malecki et al. (2004) reported reliability coefficient alphas of .96 to .97 for the total scale and .92 to .96 for the frequency subscales. Testretest reliability yielded coefficient alphas of .75 to .78 for the total scale over an 8- to 10-week period and moderate correlations with two other well-known social support scales (see Malecki et al., 2004). In this study, coefficient alphas of .94 for the Parent Support subscale and .95 for the School Personnel Support subscale were found.

College-going outcome expectations. The College-Going Outcome Expectations Scale (CGOES; Gibbons, 2005) was created to measure outcome expectations for college going and is designed for middle school students. No scale could be found to measure this type of outcome belief in younger adolescents. Items in the CGOES represent five domains: Bandura's (1997) original three domains (material, social approval, and self-evaluation) and two additional outcome domains (relational and generative) identified by Shoffner, Newsome, and Barrio (2004). Researchers with expertise in outcome expectations coded the 28 items to ensure they represented one of the five domains and that they were, in fact, measures of outcome expectations.

Of the 28 items, 13 represent the Positive Outcome Expectations subscale and 15 represent the Negative Outcome Expectations subscale. Students responded to each item using a 4-point Likert-type scale ranging from 1 (don't believe at all) to 4 (definitely believe). Items were worded both negatively (e.g., "It will be hard for me to pass my classes") and positively (e.g., "I will gain respect from others"). We conducted a factor analysis that revealed the positive and negative items represented two separate constructs rather than a continuum and were therefore scored separately; higher scores on the positive stems indicated more positive outcome expectations and higher scores on the negative stems indicated more negative outcome expectations. In our study, the Positive Outcome Expectations subscale had a Cronbach's alpha of .84 and the Negative Outcome Expectations subscale had a Cronbach's alpha of .87.

Demographics. Respondents reported their age, gender, race, mother's and father's education level, current career choice, educational plans and goals, and career influences. In addition, a short parent survey helped determine parents' education level and current job status. 
Procedure

All seventh-grade students in each school were invited to participate. The first author went to each school, read a brief introduction regarding the purpose of the study to each class, and responded to any questions. Students who returned the consent form and parent survey by the deadline completed the surveys during class time; they received a small gift as a thank-you for their participation. Students who did not return the consent forms were given time to read silently in the classroom. No penalty was given to those students who chose not to participate in the study.

Results

As described earlier, although 275 participants returned parental consent forms, only 272 included the parent survey, which was required for inclusion in the study. Participants completing each individual assessment ranged from 255 to 270, with incomplete assessments removed for analysis purposes. For the PFGCS group, there were 51 boys and 57 girls; the nonPFGCS group was composed of 65 boys and 97 girls. A total of 103 PFGCS participants completed all of the inventories and were, therefore, included in the path analysis.

Nearly all participants indicated plans to attend some type of school after high school, and approximately half anticipated earning a graduate degree. A one-way analysis of variance (ANOVA) was conducted to determine goal differences between PFGCSs and their non-PFGCS peers. The comparison suggested a statistically significant difference in educational goals $(\mathrm{F}=$ 6.35 , $\mathrm{df}=1, \mathrm{p}<.05$ ). PFGCSs had a mean educational goal of 6.92 ( $\mathrm{SD}=2.51$; just below graduating from a 4-year university), whereas non-PFGCSs had a mean educational goal of 7.59 ( $\mathrm{SD}=1.83$; between graduating from a 4-year university and entering graduate school).

A correlation matrix was computed to examine the relationships among the scale scores for firstgeneration students. The correlation matrix is presented in Table 1. As predicted, the selfefficacy scores were positively and significantly related to each other, the social support scores (parental and school personnel support), and the Positive Outcome Expectations subscale. Selfefficacy was also negatively and significantly related to perceived barriers. No significant relationship was found between self-efficacy scores and the Negative Outcome Expectations subscale. Perceived barriers were also negatively and significantly related to the Positive 
Outcome Expectations subscale. In addition, perceived social support was positively and significantly related to the Positive Outcome Expectations subscale. Few significant relationships were found between negative outcome expectations and other perceptions for first-generation students.

TABLE 1

Correlation of Means Between Measures for Prospective

\section{First-Generation College Students}

$\begin{array}{lllllll}\text { Variable } & 1 & 2 & 3 & 4 & 5 & 6\end{array}$

$\begin{array}{lllllll}\text { 1. Self-efficacy } \quad-- & -.30 * * & .42 & .28 & .56 * * & .13\end{array}$

2. Perceived barriers $\quad---.12 \quad-.08 \quad-.38 * * .09$

3. Parental support $\quad--.71 * * .48 * * .21 * *$

4. School personnel $\quad--.47 * * .22 * *$

Support

5. Positive Outcome $\quad--\quad .05$

Expectations subscale

6. Negative Outcomes

Expectations subscale 
${ }^{* *} \mathrm{p}<.01$.

To test for homogeneity of variance assumptions, we conducted a series of Hartley's [F.sub.max] tests (Kirk, 1968) using the harmonic means of the cell sizes. The harmonic mean was used to account for nonsimilar cell sizes in the study (Howell, 2002). These analyses led to retention of the equal variance null hypothesis in five of the six cases. This suggests that, for all but the Parent Support subscale, no violation of homogeneity' of variance occurred. Variance issues, then, may play a role in results related to parent support.

Social-Cognitive Comparisons

We conducted $2 \times 4 \times 2$ factorial ANOVAs, with gender, race/ethnicity, and first-generation status as the independent factors and the mean scores on the social-cognitive measures as the dependent factors. Only significant results are reported here (see Gibbons, 2005). For significant interaction effects, we then completed post hoc independent t tests to further analyze the results.

PFGCSs $(M=90.36, S D=14.0)$, as compared with non-PFGCSs $(M=99.19, \mathrm{SD}=13.81)$, reported lower college-going self-efficacy scores ( $\mathrm{F}=8.66$, $\mathrm{df}=1, \mathrm{p}<.005$, [[eta].sup.2] = 03). Two significant interaction effects were found as well. A significant interaction effect between gender and first-generation status was found for boys $(\mathrm{F}=5.29, \mathrm{df}=1, \mathrm{p}<.03$, [[eta].sup.2] $=$ .02), with male PFGCSs reporting lower self-efficacy expectations $(\mathrm{M}=88.35$, $\mathrm{SD}=14.85)$ than did male non-PFGCSs $(\mathrm{M}=99.36, \mathrm{SD}=13.63), \mathrm{t}(115)=-4.17, \mathrm{p}<.001$. For the second interaction effect between gender and race/ethnicity $(\mathrm{F}=2.68 \mathrm{df}=3, \mathrm{p}<.05$, [[eta].sup.2] $=$ .03), significant differences existed for only the African American students, with boys reporting lower self-efficacy expectations $(M=93.11, S D=17.00)$ than did girls $(M=99.55, S D=9.81)$, $t(81)=-2.03, p<.05$. Because of small numbers for some of the racial/ethnic groups, chance variation could have played a role in these results.

PFGCSs perceived significantly more barriers to college going than did non-PFGCSs (PFGCSs, $\mathrm{M}=$ 92.97, $\mathrm{SD}=$ 23.85; non-PFGCSs, $\mathrm{M}=75.17, \mathrm{SD}=22.12 ; \mathrm{F}=16.21, \mathrm{df}=1, \mathrm{p}<.001$, [[eta].sup.2] =.06). A main effect by race/ethnicity was found as well $(\mathrm{F}=3.18 \mathrm{df}=3, \mathrm{p}<.05$, [[eta].sup.2] = .04). A comparison of means by racial/ethnic groups was completed to examine which groups perceived more barriers. White participants perceived significantly fewer barriers to college going than did any other racial/ethnic group $(\mathrm{M}=70.91$, $\mathrm{SD}=19.38)$, whereas Hispanic/Latino participants perceived the most barriers to college ( $\mathrm{M}=95.51$, SD = 25.12). Interaction effects for first-generation status and race/ethnicity did not achieve significance. An 
interaction effect between first-generation college-going status and gender was found ( $F=6.75$, $\mathrm{df}=1, \mathrm{p}<.01$, [[eta].sup.2] = .03), however. Male students $(\mathrm{M}=93.01, \mathrm{SD}=23.88)$ perceived more barriers to college going than did female students $(\mathrm{M}=74.56, \mathrm{SD}=21.99)$, regardless of first-generation status, $\mathrm{t}(116)=5.40, \mathrm{p}<.001$.

For parent support, there was no significant difference by first-generation status $(\mathrm{F}=2.03, \mathrm{df}=\mathrm{l}$, $\mathrm{p}>.05$ ), but a significant interaction effect between first-generation status and race/ethnicity was found ( $\mathrm{F}=3.03, \mathrm{df}=3, \mathrm{p}<.03$, [[eta].sup.2] $=.04)$. African American students differed in their perception of parent support, with PFGCSs $(M=53.25, S D=14.25)$ perceiving less parent support than did non-PFGCSs $(\mathrm{M}=59.97, \mathrm{SD}=11.15), \mathrm{t}(80)=-2.23, \mathrm{p}<.05$. For school personnel support, only an interaction effect between first-generation status and race/ethnicity' was detected ( $\mathrm{F}=3.01, \mathrm{df}=3, \mathrm{p}<.05$, [[eta].sup.2] $=.03)$. Two significant results were found in the post hoc testing. First, Hispanic/Latino participants differed by first-generation status, with PFGCSs ( $(M=55.46, S D=14.94)$ perceiving less school personnel support than did nonPFGCSs $(\mathrm{M}=64.57, \mathrm{SD}=7.21), \mathrm{t}(62)=1.58, \mathrm{p}<.05$. The other ethnicity group also reported differences in perceived school personnel support, with PFGCSs $(M=56.92, \mathrm{SD}=9.62)$ reporting higher support than did non-PFGCSs ( $\mathrm{M}=45.28, \mathrm{SD}=15.88), \mathrm{t}(28)=2.27, \mathrm{p}<.05$. Some of the racial/ethnic groups had a small number of participants, so caution should be taken when reviewing these results.

For the Positive Outcome Expectations subscale, PFGCSs reported lower positive outcome expectations than did non-PFGCSs $(\mathrm{F}=7.43, \mathrm{df}=1, \mathrm{p}<.008$, [[eta].sup.2] $=.03)$. No interaction effects were found. For the Negative Outcome Expectations subscale $(\mathrm{F}=.68 \mathrm{df}=1, \mathrm{p}>.05$, [[eta].sup.2] = .003), no significant differences existed in mean scores by first-generation status for this subscale. A main effect was found for race/ethnicity $(\mathrm{F}=4.44, \mathrm{df}=3, \mathrm{p}<.005$, [[eta].sup.2] = .05). Hispanic/Latino $(\mathrm{M}=28.03, \mathrm{SD}=8.65)$ and other ethnicity $(\mathrm{M}=28.46$, SD $=8.65$ ) participants perceived more negative outcomes related to college going than did White $(\mathrm{M}=21.57, \mathrm{SD}=6.89)$ or African American $(\mathrm{M}=24.95, \mathrm{SD}=8.83)$ participants, regardless of first-generation status. Bonferonni post hoc analyses yielded a significant mean difference between the White participants and the participants of the other three racial/ethnic groups, with White students reporting significantly lower perceived negative expectations.

Social-Cognitive Model 
To examine the relationships among self-efficacy, outcome expectations, perceived barriers and supports, and intentions in PFGCSs, we performed path analyses using the LISREL statistics program. Path analysis, a specific form of structural equation modeling, was used because all variables were indicators, with no latent variables present (Raykov \& Marcoulides, 2000). Given the sample size, differences in paths by race/ethnicity and gender were not explored. We hypothesized the current SCCT model would be a good fit for this group of students, with PFGCSs' self-efficacy expectations being strongly affected by perceived barriers and weakly affected by minimal social supports. Students who did not complete all of the assessments were dropped for this part of the analysis, leaving a total of 249 participants, with 103 first-generation students and 146 non-first-generation students. Only the path analysis for first-generation students is reported.

Given the sample size, the root mean square error of approximation (RMSEA) and adjusted goodness-of-fit index (AGFI) were used to determine goodness of fit. An RMSEA of below .08 and an AGFI of above .90 would be indicators of good fit for the current SCCT model. For the PFGCSs in this study, the RMSEA was .15 and the AGFI was .76 ( $\mathrm{n}=103$, [[chi].sup.2] = 64.04, $\mathrm{df}=9$ ). On the basis of these indices, the SCCT model was not a good fit to explain the relationship between these variables and the strength of college-going intentions.

To determine the best fit for the PFGCSs, we made modifications to the original model. All variables were included in these analyses. Revised paths were drawn from the contextual influences (barriers and supports) to determine what, if any, effects they had on the other variables in the SCCT model. In addition, no research could be found that examined the relationship between negative and positive outcome expectations separately, so the effects of each of these variables on the other constructs in the model were examined as well.

A clear rationale existed for each revised path. The latest research on the relationships of contextual influences to the other SCCT variables has suggested their effects are fully mediated through self-efficacy (e.g., Lent et al., 2000). However, researchers have not always agreed on this mediation effect, and no research could be found that examined the direct relationship between contextual influences and outcome expectations, so these variables were explored in the current study. In addition, because the concept of separating negative and positive outcome expectations is new, we believed it was necessary to explore the relationship of these variables to the other SCCT constructs separately. 
The revised path model for PFGCSs is depicted in Figure 1. Goodness-of-fit statistics indicated a good fit for this model $(\mathrm{n}=103$, [[chi].sup.2] $=9.61, \mathrm{df}=9$, RMSEA $=.02$, AGFI $=.92)$. The path diagram that emerged indicated partial support for the SCCT model along with several new pathways. Perceived barriers directly affected college-going self-efficacy expectations, which then directly affected strength of college-going intentions. In addition, self-efficacy expectations directly affected both positive and negative outcome expectations, both of which also directly affected strength of college-going intentions. Parent support directly affected self-efficacy expectations as well. Each of these paths is predicted by the SCCT model, indicating partial support for the theory The revised pathways included parent support directly affecting negative outcome expectations and school personnel support directly affecting positive outcome expectations rather than being fully mediated through self-efficacy.

\section{[FIGURE 1 OMITTED]}

\section{Discussion}

Differences Between PFGCSs and Their Non-PFGCS Peers

Results from the multiple factorial ANOVAs provide evidence of differences between PFGCSs and their non-PFGCS peers related to the SCCT constructs. Similar to other studies (e.g., Bui, 2002; Horn \& Nunez, 2000), our study showed that the PFGCSs were more likely to be Hispanic/Latino, much less likely to be in a higher level math course, and much more likely to indicate entering something other than a 4-year university compared with their non-PFGCS peers. As with previous research (e.g., Johnson, 2000; Kelpe-Kern, 2000), however, most PFGCSs, like their non-PFGCS peers, planned to attend a 4-year college after high school.

College-going self-efficacy PFGCSs in this study reported lower college-going self-efficacy expectations than did their non-PFGCS peers. Self-efficacy expectations have consistently been found to directly affect career and educational intentions (Fouad \& Smith, 996), as well as interests and goals (Lent et al., 2003; Nauta \& Epperson, 2003). Therefore, because PFGCSs already indicated lower self-efficacy expectations for college-going at this young age, this finding is important. Small to moderate effect sizes may limit the meaningfulness of these results. 
Perceived barriers. By using the PEB-R, we were able to both identify the specific types of barriers perceived by PFGCSs and better understand the effect of these barriers on collage-going expectations. PFGCSs reported a higher number of perceived barriers, and specific themes emerged. Whereas non-PFGCSs perceived only barriers related to finances and school stress, PFGCSs identified finances, family issues, racial/ethnic discrimination, lack of college-educated role models, lack of college-planning guidance, negative educational role models, and lack of preparation and/or desire as perceived barriers to college going. Jackson and Nutini (2002) found some of these same issues in their work with disadvantaged middle school students. It is important to note that seventh graders are already identifying barriers that may keep them from furthering their education.

Supports. PFGCSs, with the exception of students from the other ethnicity grouping, reported less parental support for education than did their non-PFGCS peers. Because parents have been identified as the primary influence on career development (Nauta \& Kokaly, 2001; Otto, 2000), this finding is a major concern. These same students reported lacking role models and guidance for educational planning, so it may be that parents of PFGCSs are unable to provide more than passive support for college going. Possible issues with homogeneity of variance, however, suggest this finding be viewed with caution.

Outcome expectations. PFGCSs also reported lower positive outcome expectations related to college going than did their non-PFGCS peers. This finding indicates PFGCSs believe going to college may result in fewer positive results for them than for other students. Because outcome expectations have also been found to directly affect intentions, interests, and goals (Kahn, 2001; Lopez, Lent, Brown, \& Gore, 1997), this result is important for considering the career and academic development of these students. It is interesting that no differences were found by firstgeneration status for negative outcome expectations. All the middle school students in this study appear to perceive low to moderate negative expectations about what would happen if they attended college.

PFGCSs' within-group differences. Not all PFGCSs are the same. Several gender differences were found. First, male PFGCSs perceived more barriers than did female PFGCSs. Second, male PFGCSs reported lower college-going self-efficacy than did male non-PFGCSs. Because selfefficacy expectations are so integral to the career and educational development process, this gender difference should not be overlooked. 
Additionally, some differences by race/ethnicity were found. Female African American PFGCSs demonstrated higher self-efficacy expectations than did their African American non-PFGCS peers. African American PFGCSs reported perceiving less parental support than did their African American non-PFGCS peers. In addition, Hispanic/Latino students had more negative collegegoing outcome expectations and perceived the highest level of perceived barriers to college going. Hispanic/Latino PFGCSs also perceived less school personnel support than did their Hispanic/Latino peers whose parents had education beyond high school. These results are in line with the few studies that have included enough Hispanic/Latino participants to test comparisons (Luzzo \& McWhirter, 2001; McWhirter, 1997). Overall, it appears Hispanic/Latino PFGCSs have even more needs than do other first-generation students and may require additional interventions. Small participant numbers, however, may have contributed to the fairly small effect sizes, so further investigation of these initial results is warranted.

SCCT Variables and First-Generation Students

The current SCCT model was a partial fit in explaining the college-going expectations of PFGCSs. As in the SCCT model, self-efficacy directly affected outcome expectations and both constructs directly affected strength of intentions. In addition, contextual influences (barriers and supports) affected self-efficacy and outcome expectations. However, this study demonstrated evidence that, for this population, outcome expectations may need to be modified in the SCCT model, and the effects of barriers and supports may directly influence outcome expectations rather than being fully mediated through self-efficacy.

Outcome expectations. Evidence suggests that, at least for college-going expectations, outcome expectations may need to be divided into positive and negative expectations. Within the modified model, it appears these expectations are affected by proximal influences in different ways, and their effects on intentions are different as well. As in the original SCCT model, both positive and negative outcome expectations are directly affected by self-efficacy. However, negative outcome expectations also directly affect college-going intentions, suggesting they are not merely mediated through positive outcome expectations. Generally, outcome expectations have been found by other researchers (e.g., Kahn, 2001; Lopez et al., 1997) to directly affect intentions, interests, and goals. Given the specific paths to and from negative and positive outcome expectations, paying attention to negative outcome expectations seems vitally important when working with PFGCSs; counselors cannot solely focus on raising positive expectations but must challenge negative expectations as well. 
Perceived barriers. In both the original and modified models, the effect of perceived barriers on college-going intentions is fully mediated through self-efficacy expectations. In the PFGCS model, however, barriers directly affected negative outcome expectations as well. This may indicate an increased intensity for PFGCSs; perceived barriers affect their belief in their ability to do the tasks necessary to get to college as well as their belief in their ability to succeed if they do arrive at college. Finding ways to challenge the validity of the perceived barrier or work through the barrier itself may be needed.

Perceived supports. For PFGCSs in this study, college-going self-efficacy expectations were directly and positively affected by perceived parental support while being directly and negatively affected by perceived barriers. However, parental support also directly and positively affected negative outcome expectations, whereas perceived school personnel support did not directly affect self-efficacy expectations at all, but rather affected positive outcome expectations.

If parental support has a positive relationship with negative outcome expectations, then it may be PFGCSs are receiving mixed messages about college going from their parents. However, this support of their education does seem to have a positive effect on self-efficacy as well, so at least some part of that support is positively affecting student belief systems. Perhaps these parents voice support for education but also express doubts about being able to pay for college.

The direct relationship between school personnel support and positive outcome expectations for PFGCSs suggests school environment can be a powerful influence on college-going expectations. Feeling supported in school now helps students believe that in the future, college will be a positive place as well.

Recommendations and Conclusion

On the basis of all of these results, it appears the SCCT model may warrant further investigation in two areas. First, the measurement of both positive and negative outcome expectations used here was suggested by Shoffner et al. (2004) based on the results of their focus group research. The slight negative correlation between the means on the Negative Outcome Expectations and Positive Outcome Expectations subscales in this study strongly suggested negative items cannot be reverse scored. The outcome represented by the two belief systems subscales may be related, but they still seem to be distinct from each other. Second, the addition of first-generation status 
as a background variable seems to be useful. Parents' education level clearly has a direct impact on the educational and career aspirations of students. Up to now, gender, race/ethnicity, and socioeconomic status were the primary background influences included in SCCT research. It is suggested that first-generation status be added when exploring career and educational development because of the strong impact it has on participants' self-efficacy and outcome expectations. These new contributions to SCCT research should be studied further with different types of participants, which might include inner-city youth, participants outside of the Southeast, or participants from ethnic groups not well represented in this study (e.g., Asian American or Native American students).

Additional research on PFGCSs is also needed. In particular, longitudinal comparisons are needed to identify differences and changes between PFGCSs and their non-PFGCS peers throughout high school. Intervention studies designed to help reduce barriers, raise self-efficacy and outcome expectations, or raise social supports would be helpful in determining effective means of addressing these variable issues. Additional studies of within-group differences are needed, as well as investigations of the support systems that directly affect PFGCSs.

Several limitations of this study limit generalizability. First, the participants represented only students from a single U.S. state. Participating schools were selected based on specific demographic criteria (free or reduced lunch, race/ethnicity percentages). In addition, the relatively low response rate and small numbers for some groups may also limit generalizability. Second, the surveys were based on student self-report only. However, given the powerful influence of self-efficacy expectations, the perceptions of the students themselves were the primary interest in this study. Third, some of the assessments used in this study are new and have limited evidence of reliability and validity, which may affect the generalizability of the results. Finally, in several cases, the effect sizes for the factorial ANOVAs were small to moderate, even though results were statistically significant. Therefore, the practical significance of these results may be less strong.

Generally speaking, the college-going expectations of PFGCSs appear to be different from their non-PFGCS peers in several ways, as early as seventh grade, and SCCT seems to be a useful way of conceptualizing college-going intentions for this population. This research suggests clues to ways to assist a needy population and provides researchers and practitioners with the next steps toward future work with PFGCSs. 


\section{References}

Bandura, A. (1997). Self-efficacy: Else exercise of control. New York, NY: Freeman.

Bui, K. V. T. (2002). First-generation college students at four-year university: Background characteristics, reasons for pursuing higher education, and first-year experiences. College Student Journal, 36, 3-11.

Flores, L. Y., \& O'Brien, K. M. (2002). The career development of Mexican American adolescent women: A test of social cognitive career theory, Journal of Counseling Psychology, 49,14-27.

Fouad, N. A., \& Smith, P. L. (1996). A test of a social cognitive model for middle school students: Math and science. Journal of Counseling Psychology, 43, 338-346.

Gibbons, M. M. (2005).College-going belief of prospective first-generation college students: Perceived barriers, social supports, self-efficacy, and outcome expectations. Ann Arbor, MI: ProQuest Dissertation Services.

Horn, L., \& Nunez, A. (2000). Mapping the road. To college; First-generation students' math track, planning strategies, and context of' support (NCES Report 00-153). Washington, DC: U.S. Department of Education, National Center for Education Statistics. Howell, D. C. (2002). Statistical methods for psychology (5th ed.). Pacific Grove, CA: Duxbury Jackson, M. A., \& Nutini, C. D. (2002). Hidden resources and barriers in career learning assessment with adolescents vulnerable to discrimination. The Career Development Quarterly, 51, 56-77.

Johnson, L. S. (2000). The relevance of school to career: A study in student awareness. Journal of Career Development., 26, 263-276. 
Kahn, J. H. (2001). Predicting the scholarly activity of counseling psychology students: A refinement and extension, journal of Counseling Psychology, 48, 344-354.

Kelpe-Kern, C. W. (2000). College choice influences: Urban high school students respond. Community College Journal of Research \& Practice, 24, 487-494.

Kenny, M. E., Blustein, D. L., Chaves, A., Grossman, J. M., \& Gallagher, L. A. (2003), The role of perceived barriers and relational support in the educational and vocational lives of urban high school students, Journal of Counseling Psychology, 50, 142-155.

Kirk, R. E. (1968). Experimental design: Procedures for the behavioral sciences. Belmont, CA: Brooks/Cole.

Lent, R. W., \& Brown, S. D. (1996). Social cognitive approach to career development: An overview. The Career Development Quarterly, 44, 310-321.

Lent, R. W., Brown, \$. D., \& Hackett, G. (1994). Toward a unifying social cognitive theory of career and academic interest, choice, and performance. Journal of Vocational Behavior, 45, 79122.

Lent, R. W., Brown, S. D., \& Hackett, G. (2000). Contextual supports and barriers to career choice: A social cognitive analysis. Journal of Counseling Psychology. 47 36-49. Lent, R. W., Brown, S. D., Nota, L., \& Soresi, S. (2003). Testing social cognitive interest and choice hypotheses across Holland types in Italian high school students. Journal of Vocational Behavior, 62, 101-118.

Lopez, F. G, Lent, R. W., Brown, S. D., \& Gore, P. A. (1997). Role of social-cognitive expectations in high school students' mathematics-related interest and performance. Journal of Counseling Psychology, 44, 44-52. 
Luzzo, D. A. (1993). Ethnic differences in college students' perceptions of barriers to career development, Journal of Multicultural Counseling and Development, 44, 44-52.

Luzzo, D. A., \& McWhirter, E. H. (2001). Sex and ethnic differences in the perception of educational and career-related barriers and levels of coping efficacy. Journal of Counseling \& Development, 79, 61-67.

Malecki, C. K., Demaray, M. K., \& Elliott, S. N. (2000). Child and Adolescent Social Support Scale. DeKalb, IL: Author.

Malecki, C. K., Demaray, M. K., \& Elliott, S. N. (2004). A working manual an the development of the Child and. Adolescent Social Support Scale. DeKalb, IL: Author.

McWhirter, E. H. (1997), Perceived barriers to education and career: Ethnic and gender differences. Journal of Vocational Behavior, 50, 124-140.

McWhirter. E. H. (2000). Perception of Educational Barriers Scale. Lincoln, NE: Author.

McWhirter, E. H., Rasheed, S., \& Crothers, M. (2000). The effects of high school career education on social-cognitive variables. Journal of Counseling Psychology, 47, 330-341.

National Information Center for Higher Education Policymaking and Analysis. (2002). Collegegoing rates of high school graduates, directly from high school. Retrieved from http://www.higheredinfo.org

Nauta, M. M., \& Epperson, D. L., (2003). A longitudinal examination of the social-cognitive model applied to high school girls' choices of nontraditional college majors and aspirations. Journal of Counseling Psychology 50, 448-457. 
Nauta, M. M., \& Kokaly, M. L. (2001). Assessing role model influences on students' academic and vocational decisions. Journal of Career Assessment, 9, 81-99.

Nunez, A., \& Cuccaro-Alamin, S. (1998). First generation students: Undergraduates whose parents never enrolled in postsecondary education (NCES Report 98-082 ). Washington, DC: U.S. Department of Education, National Center for Education Statistics.

Otto, L. B. (2000). Youth perspectives on parental career influence. Journal of Career Development, 27, 111-118.

Ravkov, T., \& Marcoulides, G. A. (2000). A first course in structural equation modeling. Mahwah, NJ: Erlbaum.

Rojewski, J. W., \& Hill, R. B. (1998). Influence of gender and academic risk behavior on career decision-making and occupational choice in early adolescence. Journal of Education, for Students Placed at Risk, 3, 265-287.

Shoffner, M. F., Newsome, D., \& Barrio, C.A. (2004). Young adolescents' outcome expectations: A qualitative study. Manuscript submitted for publication.

Terenzini, P. T., Springer, L., Yaeger, P. M., Pascarella, E. T., \& Nora, A. (1996). First generation students: Characteristics, experiences, and cognitive development. Research in Higher Education, 37, 1-22.

Turner, S. L., ck Lapan, R. T. (2002). Career self-efficacy and perceptions of parent support in adolescent career development. The Career Development Quarterly. 31, 44-55.

Vargas, J. H. (2004). College knowledge: Addressing in formation barriers to college. Boston, MA: The Education Resources Institute. 
Venezia, A., Kirst, M. W., \& Antonio, A. L. (2003). Fix K-16 disconnections, or betray the college dream. Education Digest, 68, 34-40.

Warburton, E. C., Bugarin, R., Nunez, A., \& Carroll, C. D. (2001). Bridging the gap: Academic preparation mid postsecondary success of first-generation students (NCES Report 2001-153). Washington, DC: U.S. Department of Education, National Center for Education Statistics.

York-Anderson, D. C., \& Bowman, S. L. (1991). Assessing the college knowledge of firstgeneration and second-generation college students. Journal of College Student Development, 32, 116-122.

Melinda M. Gibbons, Department of Educational Psychology and Counseling, University of Tennessee; L. DiAnne Borders. Department of Counseling and Educational Development, University of North Carolina at Greensboro. Correspondence concerning this article should be addressed to Melinda M. Gibbons, Department of Educational Psychology and Counseling, University of Tennessee, 441 Claxton Complex, Knoxville, TN, 37996 (e-mail: mgibbon2@utk.edu). 